\title{
Establishing the First Geriatric Medicine Fellowship Program in Ghana
}

\author{
Akye Essuman, MBChB, FWACP, FGCP, *广 Katherine J. Gold, MD, $\$$ II Caroline Vitale, MD," \\ Ghazwan Toma, MD, ${ }^{\S}$ Christine Cigolle, MD, ${ }^{\S} \|$ Mawuli Gyakobo, PhD, FWACP, MBChB, \\ Kathryn Spangenberg, MD, FGCP, ${ }^{* *}$ Kwasi Odoi-Agyarko, MBChB, PhD, FGCP, \\ Eric Skye, MD, ${ }^{\S}$ and Philip Zazove, $M D,{ }^{\S}$ A Collaboration Between the University of Michigan \\ and the Ghana College of Physicians and Surgeons
}

As life expectancy in Ghana improves, a large and growing population of older adults require healthcare. Despite governmental support for the care of older adults, there have been no geriatricians and no in-country educational path for those desiring to become specialists in this field. In fact, 23 of 54 countries in sub-Saharan Africa (SSA) lack even a single geriatrician. We describe a novel and collaborative approach used to develop the first geriatric training fellowship in Ghana. Faculty from the Ghana College of Physicians and Surgeons and the University of Michigan worked together to develop a rigorous and evidence-based geriatrics curriculum, based on US standards but adapted to be appropriate for the cultural, economic, educational, and social norms in Ghana. This approach led to a strong training model for care of older adults while also strengthening the ongoing collaboration between the two partner universities in Ghana and the United States. The fellowship has been inaugurated in Ghana and can serve as a concrete educational model for other countries in SSA. J Am Geriatr Soc 67:1718-1723, 2019.

From the "Department of Community Health, School of Public Health, University of Ghana, Accra, Ghana; 'Department of Family Medicine, Korle-Bu Teaching Hospital, Accra, Ghana; ${ }^{\ddagger}$ Faculty of Family Medicine, Ghana College of Physicians and Surgeons, Accra, Ghana; ${ }^{\S}$ Department of Family Medicine, University of Michigan Health System, Ann Arbor, Michigan; "Department of Obstetrics \& Gynecology, University of Michigan Health System, Ann Arbor, Michigan; "Department of Internal Medicine, Division of Geriatric and Palliative Medicine, University of Michigan Health System, and GRECC, VA Ann Arbor Healthcare System, Ann Arbor, Michigan; and the **Department of Family Medicine, Komfo Anokye Teaching Hospital, Kumasi, Ghana.

Address correspondence to Katherine J. Gold, MD, MSW, MS, Department of Family Medicine, University of Michigan, 1018 Fuller Street, Ann Arbor, MI 48104-1213. E-mail: ktgold@umich.edu

Twitter: @KGoldMD

Corrections added July 3, 2019, after first online publication. Akye Essuman and Mawuli Gyakobo's academic degrees have been updated for accuracy.

Twitter handles for all co-authors: @drcavitale and @philipzazove

DOI: 10.1111 /jgs.16014
Key words: Ghana; geriatrics; training; graduate medical education; older adults

\section{BACKGROUND}

$\mathrm{T}$ he older adult population in Ghana is increasing in tandem with the global pattern. ${ }^{1}$ Ghana's population of about 29 million has an estimated older adult (60 years and older) population of $7.1 \%$ in 2015 , an increase from $4.5 \%$ in $1960 .^{1-3}$ This proportion is projected to rise to $9.8 \%$ (about 5 million) by $2050 .{ }^{1,4}$ Life expectancy at birth increased from an average of 52 years in 1984 to 63.4 years in 2016 for both sexes. ${ }^{2,5}$ Despite a substantial need in Ghana, there is a dearth of trained geriatricians ${ }^{6}$ and no existing training program to educate physicians about the specialized care of the older adult.

Studies on aging in Ghana have mostly emerged only in the last 2 decades. The World Health Organization Study on Global Aging and Adult Health (SAGE) Wave 1 is the most comprehensive population-based study on the health status of older adults in Ghana. ${ }^{7}$ According to the study, older adults in Ghana report a high prevalence of one or more chronic medical conditions such as hypertension, coronary artery disease, diabetes, anemia, and depression, along with substantial prevalence of geriatric-specific conditions such as falls and mobility issues, urinary incontinence, and dementia. Clinical data from the study showed that the true prevalence of measured hypertension was much higher than the self-report, suggesting that for every person who reports a diagnosis, another three likely have undiagnosed hypertension. Among older adults, about 2 in 5 have one or more deficiencies in activities of daily living, and 1 in 5 have deficiencies in instrumental activities of daily living. 
Systematic health delivery designed for older adults as well as data from health facilities on this population is still almost nonexistent in Ghana. When we started developing this fellowship, no geriatric medicine training program existed in Ghana, and we were unaware of any practicing geriatricians. ${ }^{5,6}$ Routine primary care for older adults is provided by family/general practitioners. Even fewer healthcare providers work in rural settings, and access to healthcare is hampered by distance and transportation costs. There is a lack of training and virtually no resources to manage geriatric syndromes such as falls, mobility problems, and cognitive impairment. Although physical and occupational therapy services are covered by health insurance, they are limited to regional and tertiary health facilities, making access problematic. Overall, $10 \%$ of older persons cannot access needed healthcare, and only 2 in 5 perceive their health status as good. ${ }^{7,8}$

Most Ghanaians provide help for their aging parents and older persons in general, but this time-honored respect and care for older persons is fast eroding. Migration of the youth from rural areas to cities, increasing work and study demands on the younger workforce, and stigmatization of older adults, especially those who are frail or have dementia, have contributed to increasing isolation and neglect of older persons in African societies. A new trend where working children decline to remit aging parents contradicts the cultural expectation of reciprocity in social and economic support that existed for most Africans including Ghanaians. ${ }^{9-11}$

However, there is strong in-country support for improving care of older adults. The Ministry of Employment and Social Welfare has developed a National Aging Bill, and the National Health Insurance has a policy that exempts persons 70 years and older from paying a premium to cover basic care. ${ }^{12,13}$ Ghana has a well-organized district health system to deliver health at the primary level through district hospitals, subdistrict health centers, and community clinics known as Community-based Health Planning and Services. ${ }^{14}$ An emerging long-term home care industry is spearheaded by nongovernmental organizations and the private sector. ${ }^{15}$

To address the lack of geriatricians, the Ghana College of Physicians and Surgeons (GCPS) approved a fellowship program to train family medicine and internal medicine graduates in the discipline of geriatric medicine. The program leverages the collaboration between the Faculty of Family Medicine of the GCPS and the Department of Family Medicine, University of Michigan (UM); this collaboration began in 2008 and aims to build capacity for faculty training and facilitate residency/fellowship program development through educational exchange visits between Ghana and Michigan. We have used this international collaboration to develop a new geriatric medicine fellowship program within the Faculty of Family Medicine, GCPS (Supplementary Figure S1).

\section{METHODS}

We used the University of Michigan African Presidential Scholars (UMAPS) program to allow a senior Ghanaian faculty member to engage in focused clinical observational experiences in geriatrics and obtain academic and administrative training to run a new fellowship program. The Department of Family Medicine at UM has extensive experience developing faculty via training and fellowships and was able to support a special training experience embedded within both the Department of Internal Medicine Division of Geriatric and Palliative Medicine and the Department of Family Medicine. The Ghanaian fellowship lead (A.E.) spent 6 months at UM from August 2015 to February 2016.

\section{Clinical Training Objectives}

Clinical training entailed active observation of patient care in outpatient geriatric primary care and consultation, geriatric inpatient consultation, geriatric inpatient care in the Acute Care for the Elderly unit and community-based care facilities including a Program of All-inclusive Care for the Elderly model of care, and assisted living and extended care facilities. Clinical instruction also included access to patient electronic health records (after privacy and Health Insurance Portability and Accountability Act training and certification), participation in patient interviews, observation of use of technology and application of clinical guidelines, and discussion of cases with attending geriatric physicians.

\section{Educational Objectives}

The Ghanaian faculty member participated in monthly teaching workshops organized by the Faculty Development Institute within the UM Department of Family Medicine to help new faculty gain expertise in education and teaching. Frequent consultative meetings on training and curriculum development were held with the UM Geriatric Medicine Fellowship program directors and coordinators to guide the process of developing the fellowship curriculum.

In developing the curriculum, an extensive literature search was conducted to assess the status of geriatric care and training on the African continent. The curriculum drew from the established educational bodies, organizations, and experts, ${ }^{16-18}$ and it was amended to be consistent with the culture and structure of healthcare in Ghana. The content was organized around six main themes: (1) assessment of the geriatric patient; (2) the geriatric syndromes; (3) geriatric interdisciplinary approach to care; (4) systems of care; (5) faculty development (teaching and administration); and (6) research (modified from Raymond Yung, MB, ChB, personal communication, September 9, 2015). An initial draft was reviewed by an internal curriculum project team of family physicians and educational and curriculum experts. Their inputs were incorporated into a second draft reviewed by geriatric and palliative medicine experts, the project team, and other stakeholders at UM and in Ghana. The third draft was circulated to the project team and a final copy submitted to the academic board of the GCPS in February 2016. In addition, a portfolio of educational, clinical, and research activities for trainees was developed. Portions of the portfolio were based on the Geriatric Medicine Milestones Project to track fellows' progress across accepted milestones during fellowship training with the goal of ensuring that graduating geriatric medicine fellows from the Ghana program achieve clinical competency across specific domains including patient care, medical knowledge, systems-based practice, practice-based learning and improvement, professionalism, and interpersonal and communications skills. ${ }^{19}$ 


\section{Research Objectives}

Research experience for the UMAPS fellow was supported through participation in weekly academic writing workshops organized by UMAPS. The primary mentor (K.G.) provided hands-on experience in questionnaire design, data analysis, and manuscript writing. Guidelines were developed on research supervision in fellowship and residency programs. A designated personal librarian at the UM Taubman Health Sciences Library provided exposure to the virtual library and trained the faculty in new search engines and citation management software.

\section{Administrative Objectives}

This training involved scheduled meetings with administrators, administrative assistants, and clinical case managers within the various training sites. Discussions focused on organizing schedules and periodic assessments for fellows, recruiting and managing the program, and providing clinical services in geriatrics.

\section{RESULTS}

Although most fellowship programs in the United States and other countries are typically shorter, the Ghanaian program will last 2 years to conform to the GCPS requirements for fellowship programs. This schedule also allows fellows to continue to provide some care at their base hospitals. The overall aim of the program is to produce a physician with the requisite knowledge, skills, and attitudes to provide specialized care for older adults and to have the competency to teach and conduct research in geriatrics and gerontology. The physician should be able to provide leadership for the multidisciplinary team of health, social, and other interprofessional team members involved in the care of the older adult within the context of primary care. During the initial 5 years, the program will admit two fellows each year. The entry requirement is the completion of a 3-year residency ("membership") in family medicine or internal medicine, post-membership work experience, a valid registration with the Medical and Dental Council, and a selection interview. Trainees can opt for either government (eg, the Ministry of Health $[\mathrm{MOH}]$ ) sponsorship or other forms of sponsorship. The Ghana program incorporates clinical rotations, educational, research, and administrative activities as outlined in Table 1.

In Table 2 we illustrate a typical work week for a trainee undergoing both longitudinal and block rotations. A session may last between 4 and 6 hours. Family medicine fellows in

\section{Table 1. Structure for the Training Program in Geriatric Medicine Fellowship in Ghana}

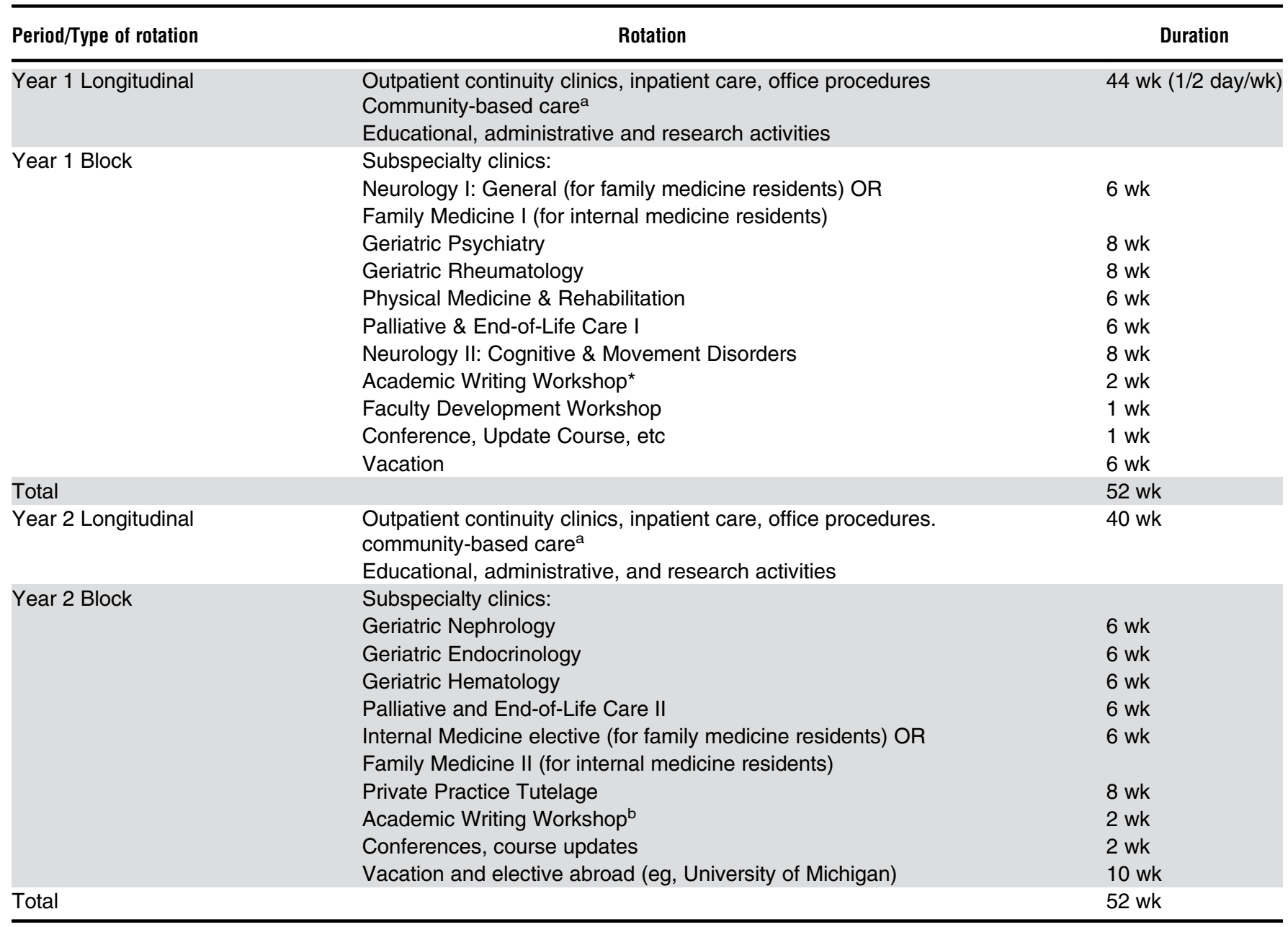

Note: Longitudinal rotations are concurrent and weekly. Block rotations are consecutive and weekly.

${ }^{a}$ Adult day care centers.

${ }^{\mathrm{b}}$ Half-day sessions. 
Table 2. Typical Average Weekly Sessions for a Geriatrics Fellow in Training

\begin{tabular}{llc}
\hline Activity & Frequency/Wk & No. of hours \\
\hline Geriatric outpatient continuity clinic & 1 session & 6 \\
Family practice/internal & 1 session & 6 \\
medicine outpatient clinic & & \\
Geriatric inpatient acute care & 1 session & 6 \\
Subspecialty clinic (rotation) & 1 session & 6 \\
Community-based care & 1 session & 4 \\
Geriatric on-call consult (weekend) & 1 session & 6 \\
Office procedures & 1 session & 4 \\
Didactics and research conference & 2 sessions & 8 \\
Scholarly activity & 1 session & 6 \\
Administrative activity & 1 session & 4 \\
Total & 11 sessions & 56 \\
\hline
\end{tabular}

training typically work an average of 40 hours a week including on-call duty, excluding educational, administrative, and research activities.

\section{Trainers and Training Sites}

Core trainers will include the principal investigator (A.E.), the project team in Ghana, and mentoring faculty from UM. Specialists from the department of internal medicine and allied health disciplines will be engaged for the subspecialty rotations. The main training site will be the family medicine clinic in the Korle-Bu Teaching Hospital, Accra. Subspecialty rotations will take place within internal medicine, allied health, and family medicine. Additional training sites will include private practices and community-based facilities (eg, adult day care programs).

\section{Assessment and Evaluation}

To provide formative fellow assessment as well as program evaluation, the fellowship will require fellows to develop a portfolio (Table 3 ) including the following:

1. List of instructive cases, procedures, and academic activities from longitudinal rotations that will be reviewed by the program director (A.E.) or a designated faculty semiannually.

2. Feedback forms (adapted from the UM Geriatric Fellowship Program Manual) completed and signed by supervisors of block rotations. This should be reviewed by designated faculty at the end of every block rotation and preferably before the start of the next.
3. Oral presentations, posters, quality improvement projects, and publications.

4. Progress report (based on the Geriatric Medicine Milestones Project) developed twice a year by the faculty for each fellow.

5. Personal program evaluations conducted annually for each fellow.

\section{Certification}

The qualifying examinations will consist of defense of a dissertation and the training portfolio plus a general oral examination. Certification will be provided by the GCPS.

\section{DISCUSSION}

In a recent survey of 54 sub-Saharan African (SSA) countries, 23 (including Ghana) had no geriatricians, only 7 had postgraduate programs, and 5 had undergraduate teaching programs. ${ }^{6}$ In the West African subregion, the University of Dakar, Senegal, is noted to have developed an innovative training program in geriatrics and gerontology to support the government's "Plan Sesame," a national free healthcare program for older adults. ${ }^{20}$ Although specialist geriatric services exist in some West African countries (eg, Nigeria, La Côte d'Ivoire, and Senegal), formal fellowship programs are nonexistent. Efforts are being made by the postgraduate colleges in the subregion to begin fellowship programs, although none has started yet. To the best of our knowledge, this will be the first in the West African subregion. We believe the current partnership could inspire the establishment of similar geriatric medicine fellowship programs in the subregion and beyond and provide geriatric medicine consultation and expertise for other West African countries.

The curriculum conforms to the expectations of established programs in both well-resourced and underresourced countries. ${ }^{16-20}$ The six thematic areas cover the essential components of general geriatrics. The longitudinal rotations take up one half day each week and are concurrent with the block rotations to provide year-round continuity of practice (a fundamental aspect of family medicine). Thus the longitudinal rotations offer a foundation on which the block rotations serve as building blocks to allow for acquisition of expertise in specific areas. Another important content is the opportunity for Ghanaian fellows to participate in an elective program in Michigan. This will provide much needed exposure to best practices in a wellresourced center, build fellows' confidence, and provide opportunity for continual international collaboration and standards

Table 3. Timelines for Assessment and Evaluation

\begin{tabular}{lllll}
\hline Time & \multicolumn{1}{c}{ Rotation or activity } & Type of assessment or evaluation & Assessment or evaluation leaders & Requirements \\
\hline $\begin{array}{l}\text { After each } \\
\text { block rotation }\end{array}$ & $\begin{array}{l}\text { Subspecialty rotation; } \\
\text { private practice }\end{array}$ & $\begin{array}{l}\text { Feedback from } \\
\text { rotations/Private practice }\end{array}$ & $\begin{array}{l}\text { Subspecialists; } \\
\text { private practitioner }\end{array}$ & $\begin{array}{l}\text { Completed and signed } \\
\text { feedback forms }\end{array}$ \\
6 months & All rotations/Activities & Progress report & Program director & Listed activities \\
1 year & 1. All rotations/Activities & 1. Progress report & 1. Program director & Portfolio \\
& 2. Program evaluation & 2. Program evaluation & 2. Fellow & Program evaluation form \\
18 months & All rotations/Activities & Progress report & Program director & Listed activities \\
2 year & 1. All rotations/Activities & 1. Progress report & 1. Program director & Portfolio \\
& 2. Program evaluation & 2. Program evaluation & 2. Fellow & Program evaluation form \\
\hline
\end{tabular}


for the program. To adapt to needs in Ghana, our fellowship has a required duration of 2 years instead of 1 year. Trainees will maintain posts in their respective base hospitals (all within the city of Accra) where they will complete their block rotations in internal medicine and family medicine, ensuring that the critical physician workforce is not compromised. Although there may be some variation by rotation, we anticipate trainees will be at their base hospitals 2 days a week and will attend lectures, rotations, and clinical training at the teaching hospital and other training sites 3 days a week.

The lack of trained geriatricians in Ghana, compared with the United States, poses a challenge to teaching new fellows. This situation is probably akin to what existed in US geriatric fellowship programs in the late 1980s when "many of these programs were extraordinarily weak and had a dearth of faculty." 21 The current geriatric program at UM is well structured and ranked among the top-10 courses of study in the United States. ${ }^{22}$ The residency and fellowship programs are integrated into the university health system with adequate faculty staffing, funding, and administrative support. Residencies and fellowships in Ghana are not part of the university system but under the jurisdiction of the GCPS, an agency of the $\mathrm{MOH}$. Limited faculty, inadequate remuneration, and lack of administrative support pose a constant challenge to the training programs; at present, faculty manage nearly all of the administrative tasks due to lack of help, straining their ability to teach. These challenges will ideally be mitigated by frequent educational materials and visits by mentors from Michigan (at least twice yearly), the use of electronic-based facilities for clinical and research meetings, and taking advantage of local expertise in the subspecialties of family medicine, internal medicine, allied health, and psychiatry for teaching. The goal is to attain an interdisciplinary approach to the training program, although it will take more time to develop a comprehensive interdisciplinary faculty with geriatric subspecialties in Ghana than in a high-income country such as the United States.

Another challenge will be the nonavailability of suitable training sites for the program because Ghana's healthcare infrastructure is inadequate. ${ }^{7,8}$ Ghana does not have acute and subacute care facilities specifically dedicated to older people and has limited finances to support long-term care. Like most African countries, existing models of long-term care in Ghana are predominantly family based. "Aged-friendly" hospitals, adult day care homes, rehabilitation centers, and other facilities for long-term care are only now emerging in the country and are largely unregulated. ${ }^{15}$ Protocols to manage geriatric syndromes such as falls and dementia are currently not included in the Standard Treatment Guidelines that guide care in Ghana. ${ }^{23}$ Appropriate and modern equipment for long-term care is lacking. Acceptance of homes for older adults is a huge sociocultural challenge in Ghana and Africa. In the wake of this reality, existing facilities will be "adapted" to suit the training program as much as possible. From a positive viewpoint, we see the fellowship as an opportunity to evaluate, improve, and situate long-term care within the sociocultural context of the Ghanaian. The program will help strengthen the development of Ghana's inadequate geriatric facilities. In the future, we anticipate hiring some of our graduates to establish new training sites to provide this infrastructure both for the program and for the people of Ghana.
The UM-Ghana Family Medicine partnership builds on existing collaborations in specialties like obstetrics/gynecology and emergency medicine that help produce the critical numbers of specialists and faculty needed to provide service and training in these disciplines in Ghana. ${ }^{24-26}$ Such collaborations can stem the tide of brain drain of young African academics and professionals to developed countries. Most emerging academics and professionals from developing countries want to experience part of their training within highly regarded institutions in developed countries; however, if they decline to return home after the period of study, there are profoundly negative impacts on healthcare staffing in the home country. Our fellowship is designed to retain graduates in the country. By policy, the $\mathrm{MOH}$ bonds all government-sponsored graduates for 5 years after their training. The graduates will either be retained at their current posts or transferred to other centers depending on training and in-country service needs. Privately sponsored graduates will be placed according to the terms of their contract. Like all other graduates of the college, they can only practice in Ghana and the West African subregion. Contact with US faculty will occur during visits by UM faculty to Ghana as well as during elective programs by residents in Michigan. We expect these exposures to best practices to build the confidence of our residents as they practice within the local context. It is our firm belief that a means to curb the brain drain from Africa is to provide collaborative opportunities to support African academics to succeed as leaders in their home institutions. Wellstructured mutually respecting international collaborations will produce content local African experts who will contribute immensely to the development of their countries.

In conclusion, we have presented an innovative model for developing a fellowship program in a resource-challenged environment. As Ghana's population continues to age, pragmatic steps are being taken at the policy level to address health and social issues relating to older adults. A fellowship program to train geriatricians in Ghana is an essential component of this effort, and a comprehensive curriculum is the first step toward that goal. The teaching of geriatrics should also be incorporated into the residency (membership) and medical students' curricula as suggested by our curriculum. We intend to report on the implementation phase and outcomes of the fellowship program in due course.

\section{ACKNOWLEDGMENTS}

We are grateful to all faculty in the participating institutions who provided training to Akye Essuman. We are also very grateful to Katie Grode, Blythe Bieber, Samuel Rentsch, Beverly Williams, and Hetty Ferguson-Laing for their administrative and secretarial support.

Financial Disclosure: Akye Essuman's training was funded by the University of Michigan African Presidential Scholars program with co-funding from the Global Health Initiative through the Department of Family Medicine (University of Michigan) and the Ghana College of Physicians and Surgeons' Endowment Fund. The University of Ghana paid his salary while on study leave in Michigan.

Conflicts of Interest: The authors have no financial conflicts of interest to disclose.

Author Contributions: Conception and design, drafting and revision of article, and final approval: Essuman and Gold. Design, revision, and final approval: Vitale, Toma, 
Cigolle, Gyakobo, Spangenberg, Odoi-Agyarko, Skye, and Zazove.

Sponsor's Role: The sponsors had no role in the design, methods, subject recruitment, data collection, analysis, or preparation of the manuscript.

\section{REFERENCES}

1. United Nations, Department of Economic and Social Affairs, Population Division. World Population Ageing. New York, NY: United Nations; 2017. ST/ESA/SER.A/408:2017.

2. World Health Statistics 2018. Monitoring Health for the SDGs, Sustainable Development Goals. Geneva, Switzerland: World Health Organization; 2018. http://www.who.int/gho/publications/world_health_statistics/2018/en/. Accessed May 25, 2018.

3. Ghana Statistical Service. Accra, Ghana. 2010 Population \& Housing Census: Summary Report of Final Results. 2012.

4. United Nations. World Population Prospects: The 2017 Revision. New York, NY: United Nations; 2017.

5. Ghana Statistical Service (GSS), Ghana Health Service (GHS), and ICF Macro. Ghana Demographic and Health Survey 2008. Accra, Ghana: GSS, GHS, and ICF Macro; 2009.

6. Dotchin CL, Akinyemi RO, Gray WK, Walker RW. Geriatric medicine: services and training in Africa. Age Ageing. 2013;42:124-128. https://doi.org/ 10.1093/ageing/afs119.

7. Biritwum R, Mensah G, Yawson A, Minicuci N. Study on Global AGEing and Adult Health (SAGE) Wave 1: The Ghana National Report. Geneva, Switzerland: World Health Organization; 2013.

8. World Health Organization. Ghana Country Assessment Report on Ageing and Health. Geneva, Switzerland: WHO; 2014.

9. Baffoe M, Dako-Gyeke M. Social problems and social work in Ghana: implications for sustainable development. Int J Dev Sustainability. 2013;2:347-363.

10. Tam WJ, Yap P. Health care for older adults in Uganda: lessons for the developing world. J Am Geriatr Soc. 2017;65:1358-1361.

11. Agyemang FA. The Survival Strategies of the Elderly in Rural Ghana [dissertation]. Legon Boundary, Accra, Ghana: University of Ghana; 2015.

12. Ministry of Gender, Children and Social Protection. Aged persons bill. Accra, Ghana: Ghana Publishing Company Ltd., Assembly Press; 2016 GPCL/A000/450/11/2016.

13. National Health Insurance Scheme. Membership. http://www.nhis.gov.gh/ membership.aspx. Accessed June 9, 2018.

14. Nyonator FK, Awoonor-Williams JK, Phillips JF, Jones TC, Miller RA. The Ghana community-based health planning and services initiative for scaling up service delivery innovation. Health Policy Plan. 2005;20:25-34.
15. Essuman A, Agyemang FA, Mate-Kole CC. Long-term care for older adults in Africa: whither now? J Am Med Dir Assoc. 2018;19:728-730.

16. Accreditation Council for Graduate Medical Education. Chicago, IL. ACGME Program Requirements for Graduate Medical Education in Geriatric Medicine Document. 2017. https:/www.acgme.org/Portals/0/PFAssets/ ProgramRequirements/125-151_geriatric_medicine_2017-07-01.pdf?ver= 2017-04-27-151548-643. Accessed June 4, 2019

17. Specialty Training Curriculum for Geriatric Medicine Curriculum. London, UK: Joint Royal Colleges of Physicians Training Board; 2013.

18. Vitale CA. University of Michigan Geriatric Medicine Fellowship Program. 2016-2017 Program Overview. https://medicine.umich.edu/dept/dgpm/geriatricmedicine/education-training/geriatric-medicine-fellowship. Accessed June 4, 2019.

19. Joint Initiative of the Accreditation Council for Graduate Medical Education, American Board of Internal Medicine, and the American Board of Family Medicine. The Geriatric Medicine Milestone Project. 2015. www.acgme.org/ Portals/0/PDFs/Milestones/InternalMedicineMilestones.pdf. Accessed November 7, 2018

20. Coumé M, Touré K, Faye A, Moreira TD. Geriatrics and gerontology in Senegal. Soins Gerontol. 2013;(100):34-37.

21. Morley JE. A brief history of geriatrics. J Gerontol Med Sci. 2004;59(11): 1132-1152. https://doi.org/10.1093/gerona/59.11.1132.

22. US News \& World Report. Best geriatric medicine programs. https://www. usnews.com/best-graduate-schools/top-medical-schools/geriatrics-rankings. Accessed July 24, 2017.

23. Republic of Ghana Ministry of Health. Standard Treatment Guidelines. 7th ed. Accra, Ghana: Ghana National Drugs Programme; 2016.

24. Michigan Medicine. Obstetrics and gynecology: global initiatives. https:// medicine.umich.edu/dept/obgyn/global-initiatives. Accessed November $8,2017$.

25. Journal of the International Institute. U-M Medicine: Long-term partnerships in Ghana. https:/quod.lib.umich.edu/j/jii/4750978.0015.209/-um-medicine-long-term-partnerships-in-ghana?rgn=main;view=fulltext. Accessed November 8, 2017.

26. Michigan Medicine, Emergency Medicine: Ghana Emergency Medicine Collaborative. https://medicine.umich.edu/dept/emergency-medicine/global/ghanaemergency-medicine-collaborative. Accessed November 8, 2017.

\section{SUPPORTING INFORMATION}

Additional Supporting Information may be found in the online version of this article.

Supplementary Figure S1: Visual summary. 